\title{
Research Paper: \\ From Leaving Home to Losing Identity: A Qualitative Study on Rough Sleeping in Drug Addicts in Iran
}

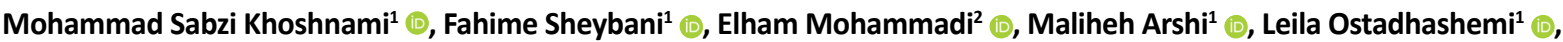 \\ "Maliheh Khalvati ${ }^{3}$ (iD)
}

1. Department of Social Work, University of Social Welfare and Rehabilitation Sciences, Tehran, Iran 2. Department of Social Work, Faculty of Social Sciences, Allameh Tabataba'i University, Tehran, Iran.

3. Faculty of Paramedical Sciences, Mashhad University of Medical Sciences, Mashhad, Iran.

\begin{tabular}{|c|c|}
\hline $\begin{array}{l}\text { Use your device to scan } \\
\text { and read the article online }\end{array}$ & Citation Sabzi Khoshnami M, Sheybani F, Mohammadi E, Arshi M, Ostadhashemi L, Khalvati M. [From Leaving Home \\
\hline 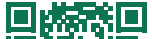 & to Losing Identity: A Qualitative Study on Rough Sleeping in Drug Addicts in Iran (Persian)]. Iranian Journal of Psychiatry and \\
\hline Fits & Clinical Psychology. 2021; 27(1):64-77. http://dx.doi.org/10.32598/ijpcp.27.1.3071.2 \\
\hline 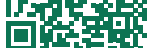 & doli'http://dx.doi.org/10.32598/ijpcp.27.1.3071.2 \\
\hline
\end{tabular}

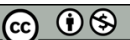

Received: 07 Aug 2019 Accepted: 12 Aug 2020 Available Online: 01 Apr 2021

Key words: Homeless, Grounded Theory, Social harm, Loss of identity, Leaving

\section{A B STRACT}

Objectives The phenomenon of rough sleeping in big cities of Iran, particularly in Tehran is a serious social problem. The term rough sleeping is mostly used for those who sleep on the public spaces including pavements, parks or under bridges. It is assumed that rough sleeping and drug addiction are linked to each other. This study aims to evaluate the process of rough sleeping based on the experiences of homeless drug addicted in Iran.

Methods This is a qualitative research. Participants were 20 homeless addicts ( 9 males and 11 females, mean age $=36.2$ years) in Tehran city who were recruited using a purposive sampling method, and sampling continued until data saturation. The data were collected through a semi-structured in-depth interview and observations. Data analysis was performed based on the grounded theory recommended by Strauss and Corbin (1998).

Results The rough sleeping process had two steps: (a) Leaving home voluntarily (to protect family or escape from family problems) or involuntarily (Due to being expelled from home and losing the roof over the head), and (b) Being homelessness which had four main categories: Elusive life, informal and contravened subsistence, involving in exploitative relationships, and loss of individual/social identity. Conclusion When leaving home and becoming rough sleeper, the individual becomes elusive, delinquent, damaged and socially rejected homeless, in addition to the risk of becoming a drug addict. Therefore, this group can be considered as a severely injured group involved in various social, legal and psychological issues. Given the complexity of the homelessness aspects in drug addicts, there is a need for coordinated interventions between individuals, families and the support systems at all levels.

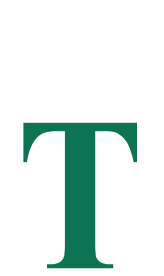

\section{Extended Abstract}

\section{Introduction}

he phenomenon of "rough sleeping" is a relatively new phenomenon in big cities of Iran. Since the beginning of modernization in Iran and with growth of migration rate to large cities and increased income gap, metropolises of Iran have faced such phenomena as suburbanization and hut living, but rough sleeping is a new social issue especially in Tehran city. It indicates to the absence of social relations that can create a sense of belonging in individuals. Therefore, lack of shelter reflects only one aspect of social deprivation in a group of people who often face multiple economic, social, physical and psychological problems. In any society, homeless people

* Corresponding Author:

Maliheh Khalvati, PhD.

Address: Faculty of Paramedical Sciences, Mashhad University of Medical Sciences, Mashhad, Iran.

Tel: +98 (513) 8846711

E-mail: ma.khalvati@yahoo.com 
are generally considered as the most vulnerable and marginalized members of urban society with little ability to organize their lives naturally. According to Tehran municipality officials, there are currently more than 20,000 rough sleepers in Tehran, of which about 2000 are reported to be women.

Due to the low number of studies and the relatively new phenomenon of rough sleeping and how it is perceived in the present situation, it is necessary to acquire and expand the knowledge and awareness about it. On the other hand, the special contextual conditions of Iran and the use of indigenous views in analyzing and monitoring of social problems every few years add importance for conducting this study. Therefore, the present study aims to investigate the status of rough sleeping in Tehran, Iran based on the experiences and perceptions of male and female drug addicts living on streets.

\section{Methods}

In this study, interviews were conducted with 20 drug addicts (9 males and 11 females) living in cardboard boxes (mean age $=36.2$ years). A purposive sampling method was used to recruit them who first had the experience of substance abuse and then experienced rough sleeping and were able to express their experiences and memories. Data were collected through a semi-structured interview and field note taking and observation. Interviews took 30-75 minutes to complete. Sampling continued until no new concepts were produced. By content analysis, some concepts were extracted and classified into categories and subcategories. After open coding, categories and subcategories were developed and paradigms were applied. Finally 1254 semantic units, 18 initial codes, 8 main categories, and 2 concepts were yielded (Table 1 ).

Table 1. The semantic units, codes, concepts, and categories extracted from interviews

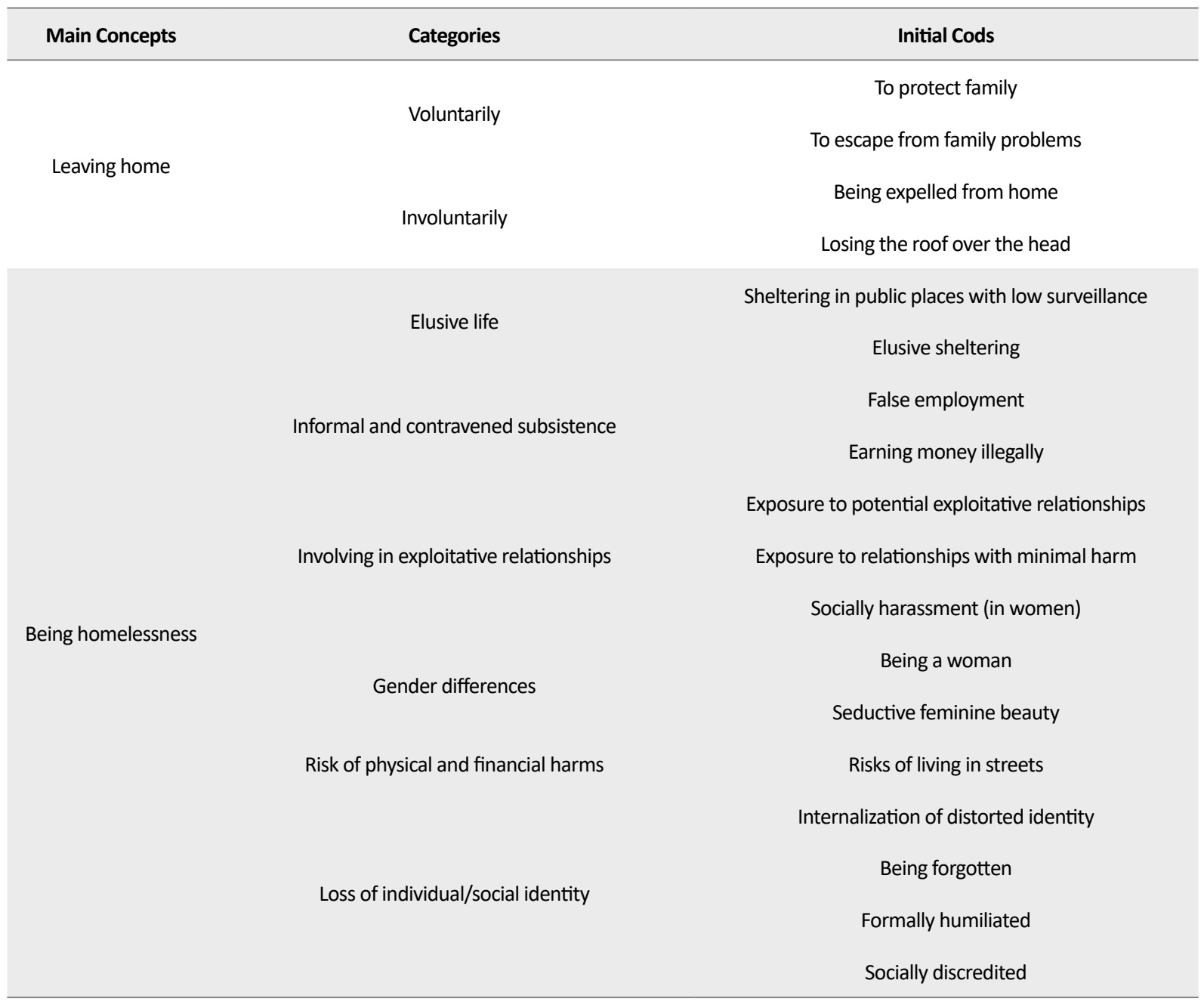




\section{Results}

Results of content analysis based on the interview with 20 participants are summarized in Table 1. The process of rough sleeping had two steps: (a) Leaving home voluntarily (to protect family or escape from family problems) or involuntarily (being expelled from home and losing the roof over the head), and (b) Being homelessness which had four main categories: Elusive life, informal and contravened subsistence, involving in exploitative relationships, and loss of individual/social identity.

\section{Discussion and Conclusion}

The present study investigated how drug addicts in Tehran become rough sleeper based on theory of "survival at any cost". The causal factor that created the phenomenon of rough sleeping was home leaving, voluntarily (to protect family or escape from family problems) or voluntarily. The contextual factor was the risk of physical and financial harms due to shelter seeking in streets. The intervening factor included gender differences (being woman and having seductive feminine beauty) which not only influenced the process of becoming/not becoming homeless, but also affected the individuals' strategies. Rough sleeping can lead to the loss of individual and social identity, internalization of distorted identity, being forgotten and formally humiliated.

\section{Ethical Considerations}

\section{Compliance with ethical guidelines}

All ethical principles are considered in this article. The participants were informed about the purpose of the research and its implementation stages. They were also assured about the confidentiality of their information and were free to leave the study whenever they wished, and if desired, the research results would be available to them.

\section{Funding}

This research did not receive any grant from funding agencies in the public, commercial, or non-profit sectors.

\section{Authors contributions}

All authors equally contributed to preparing this article.

\section{Conflicts of interest}

The authors declare no conflict of interest. 


\section{مقاله يثوهشى: از جدايى ثا هويتباختخى: ثبيين كيفى كارتن خوابى در معتادان شهر تهران}

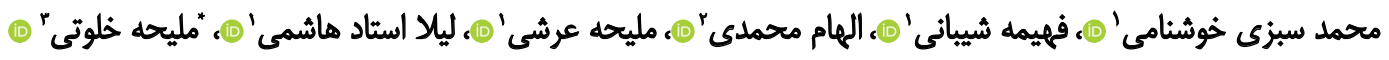

ا. كروه مددكارى اجتماعى، دانشكاه علوم توانبخشى و سلامت اجتماعى، تهران، ايران.

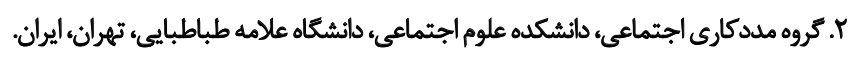

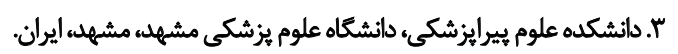

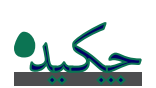

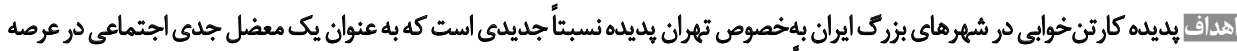

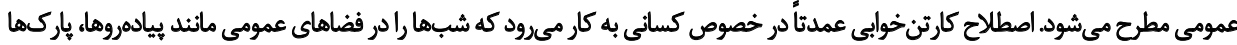

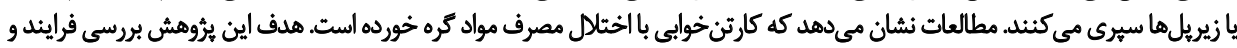

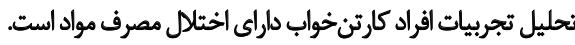

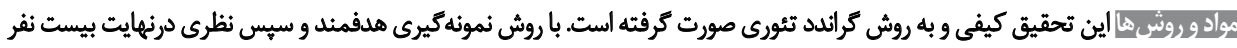

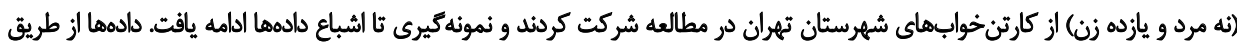

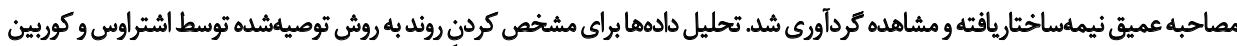

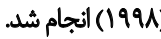

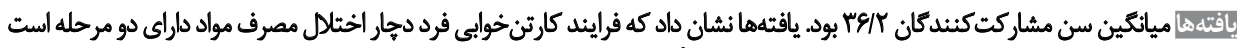

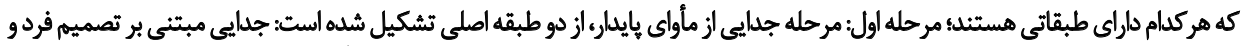

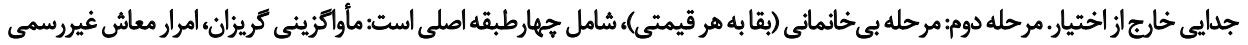

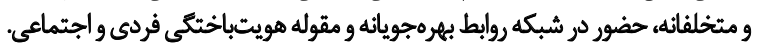

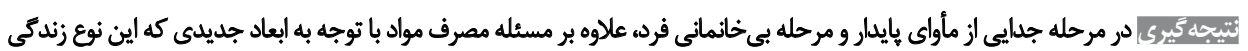

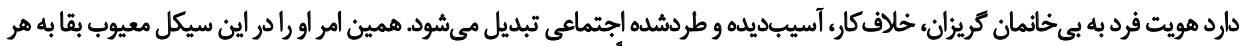

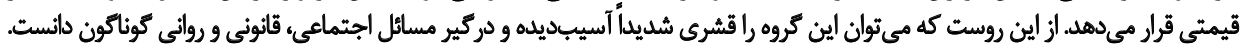

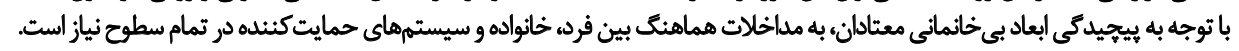

تاريخ دريافت: 19 مرداد

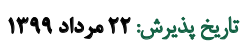

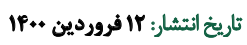

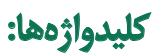
كارتن خوابي، بى خائماني، آسيب اجتماعى، نظريه

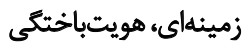

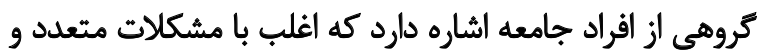

مقدمه

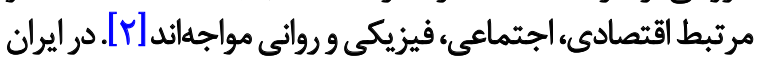

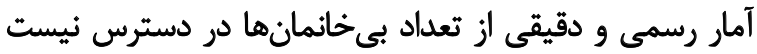

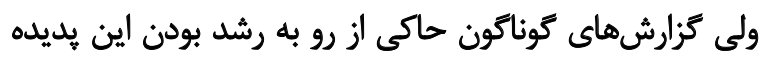

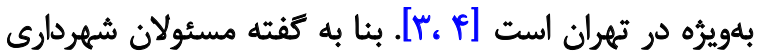

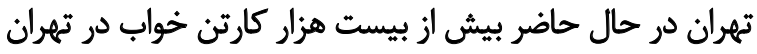

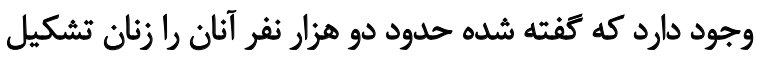

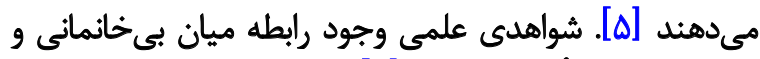

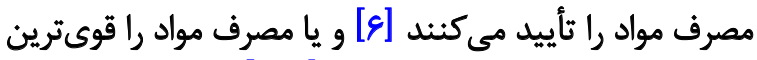

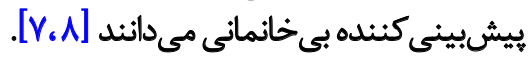

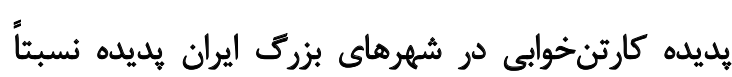

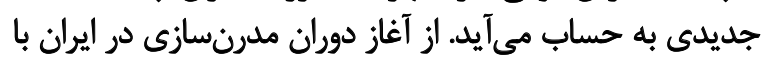

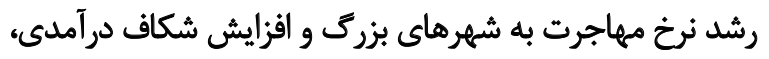

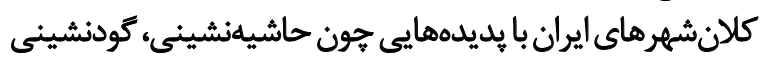

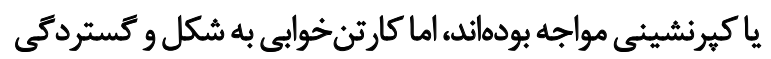

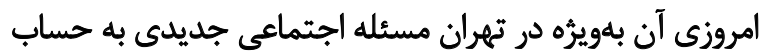

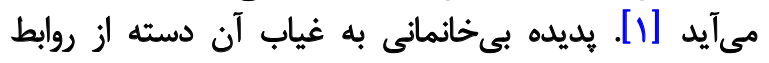

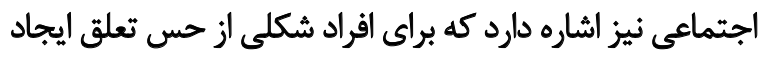

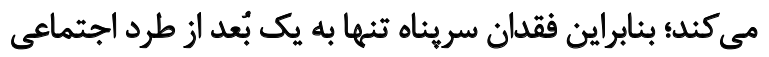


ساكن كرمخانهها و مراكز نتكهبدارى دولتي و خصوصى هستند.

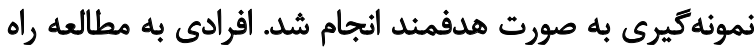

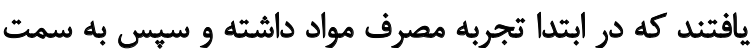

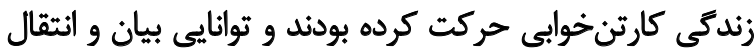

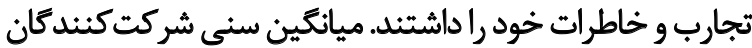

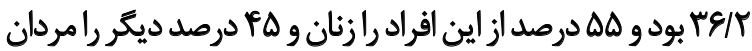

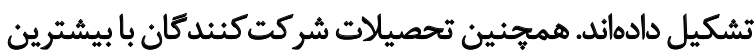

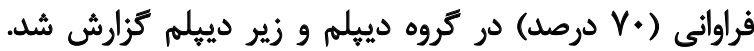

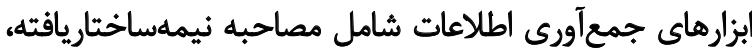

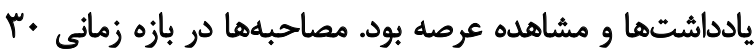

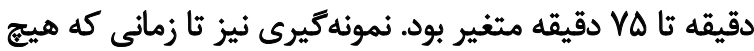

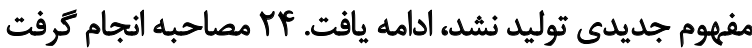

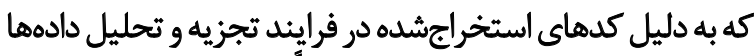

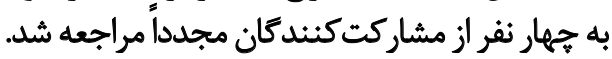

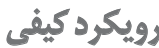

با توجه به اينكه هدف يثروهش بررسى عميق فرايند كارتنخوابى إنى

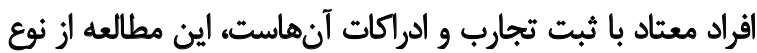

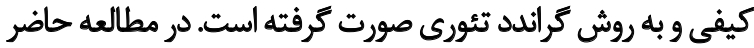

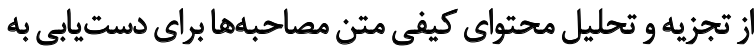

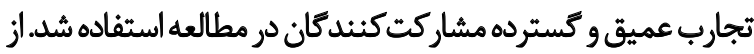

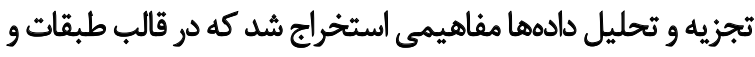

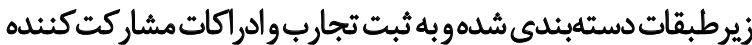

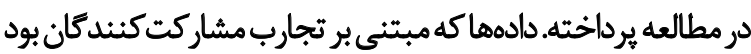

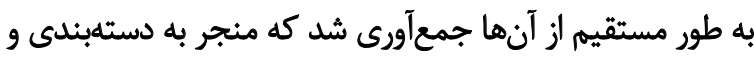
توسعه مفاهيم وطبقات طبق فرايند قياسى شد.

$$
\text { شيوها إبرا }
$$

دربر برسى ابتدايى تيمتحقيق، مكان هاى حضور شركت كنيند

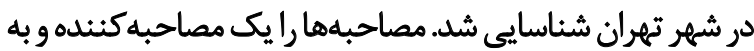

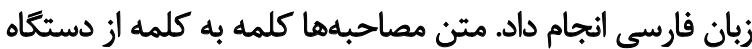

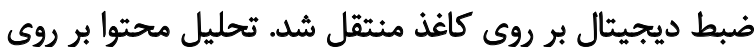

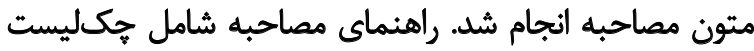

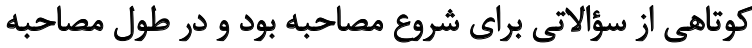

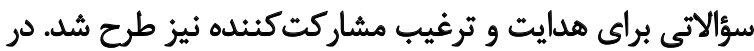

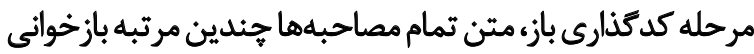

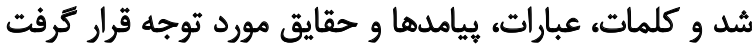

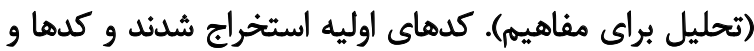

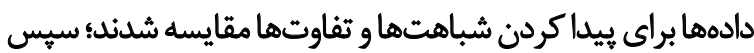

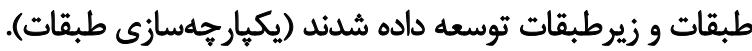

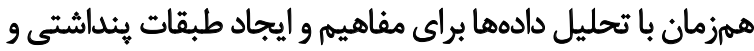

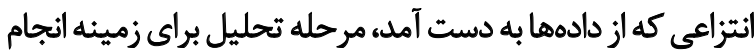

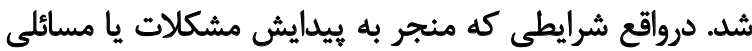

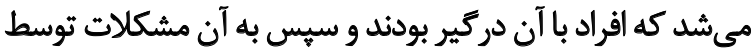

در هر جامعهاي افراد بيى خانمان عموماً آسيبذيذيرترين و

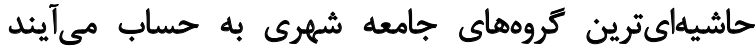

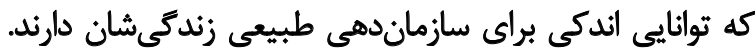

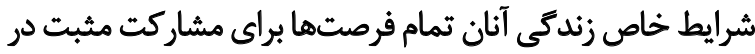

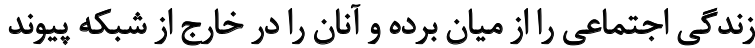

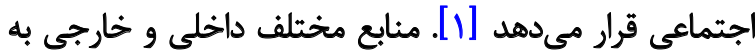

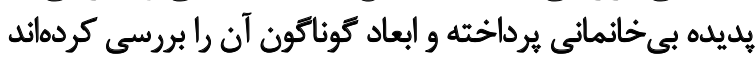

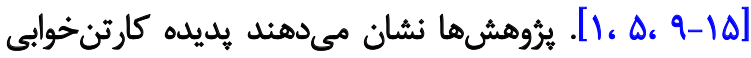

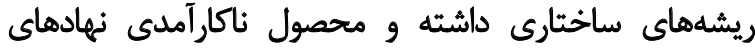

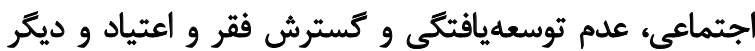

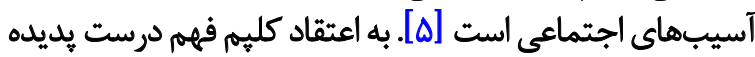

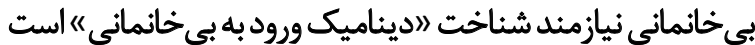

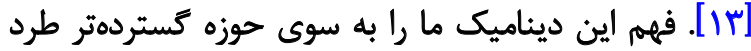

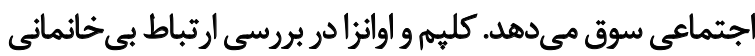

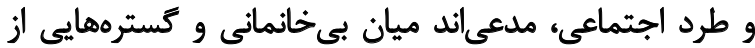

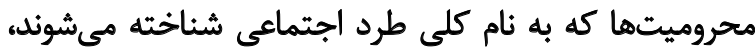

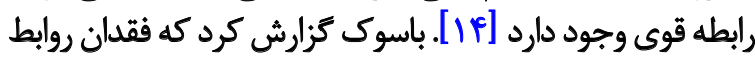

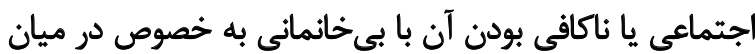

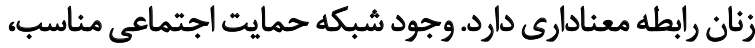

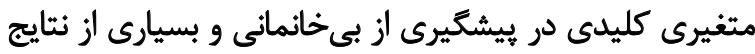

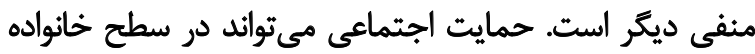

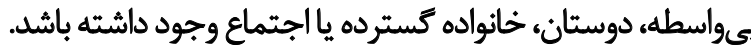

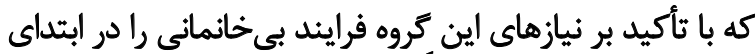

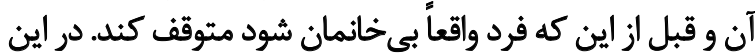

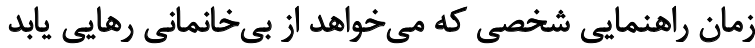

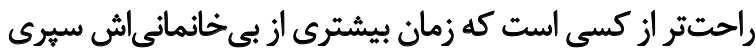

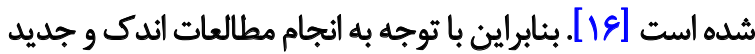

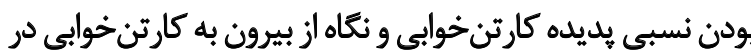

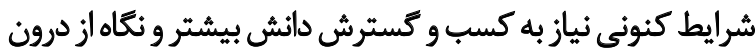

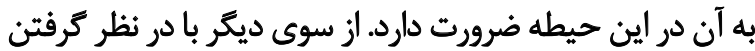

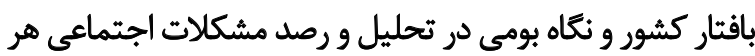

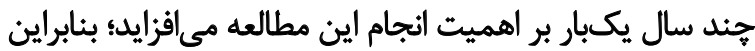

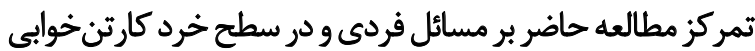

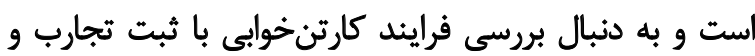

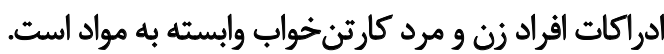

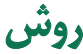

\section{مشاركت كنئد مكان}

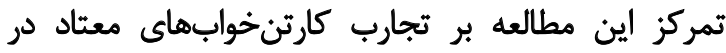

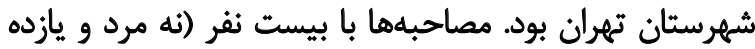

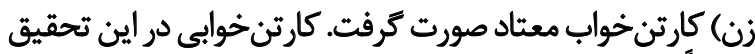

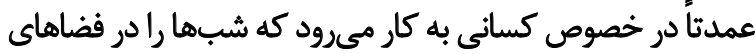

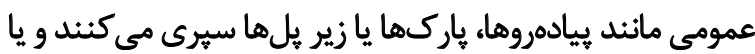




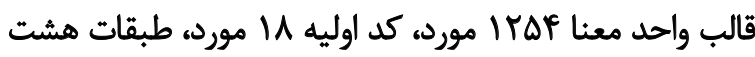

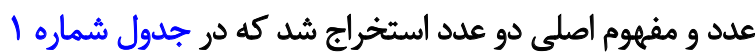

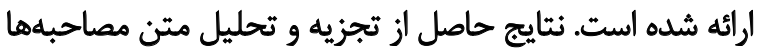

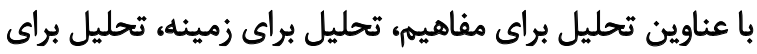
تركيب طبقات و يارادايمكذارى ارائه شده است.

\section{تحليل براي مفاهيم}

همانطور كه در جدول شماره ا آمده است، بر اساس تحليل

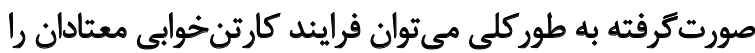

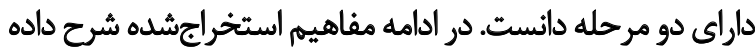
شده و مثال هايى از نقل قول هاني دآ دآنان بيان شده است.

$$
\begin{aligned}
& \text { جداليى از مأواق يايدار } \\
& \text { شرايط علّى }
\end{aligned}
$$

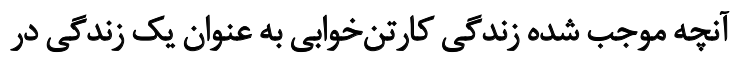

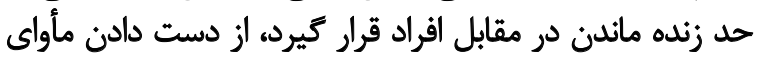

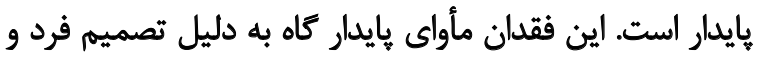

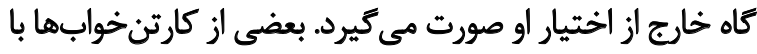

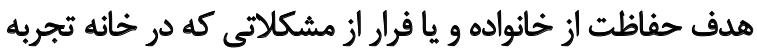

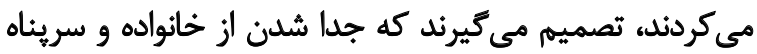

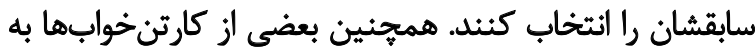

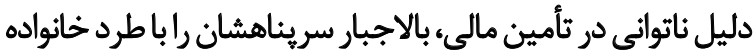
ترك مي كنيند.

\section{جدايى مبتنى بر تصميم فرد}

اين طبقه داراى دو زيرطبقه با عنوان دورى حفاظت كننده از

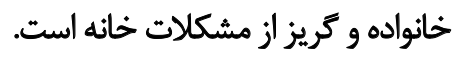

دورى حفاظت كنئده از خانواده: اين زير طبقه اشاره به رها

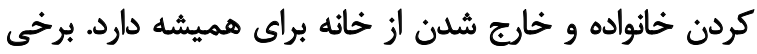

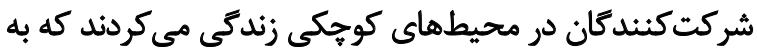

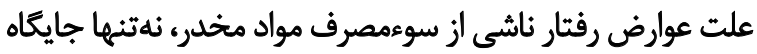

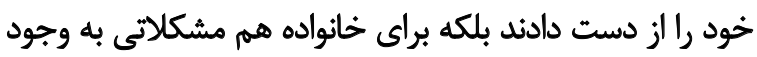

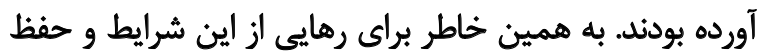

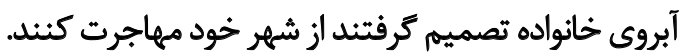

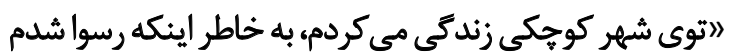

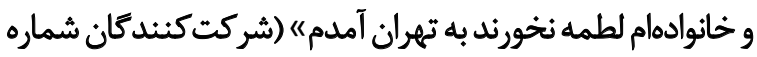
(Ir, r

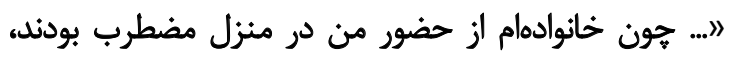

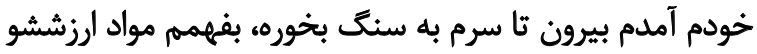

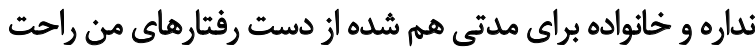
باشنده (شركت كننده شماره \&).

"اهمسايهها خيلى به خانوادام سركوفت منو مىزدن، همش

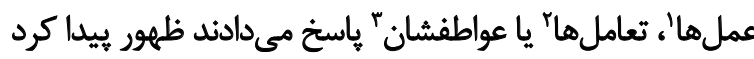
(تحليل براى زمينه).

درواقع زمينه مجموعهاى از موقعيتهايى بود كه دامنهاى

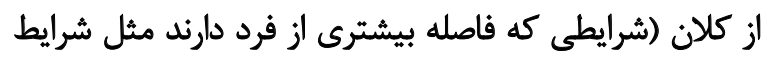

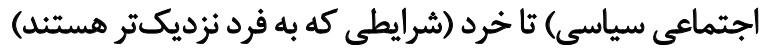

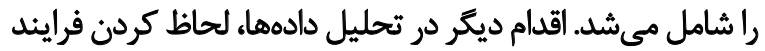

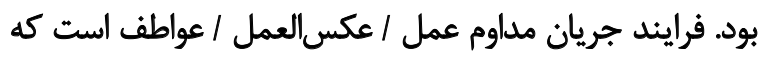

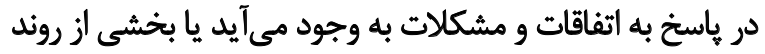

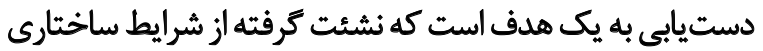

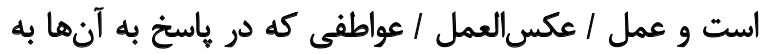

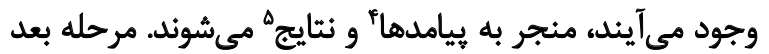

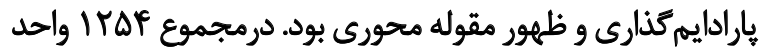
معنا، إند اوليه، هشت طبقه اصلى و دو مفهوم به دست آمد.

$$
\text { اعثبار و مقبوليت دادهانها }
$$

براي افزايش صحت و استحكام دادهها از ارزيابى مقبوليت؛

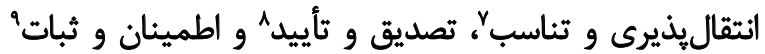

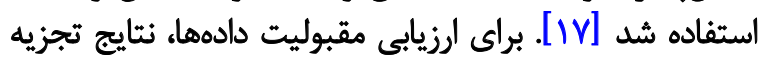

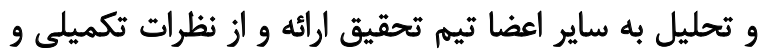

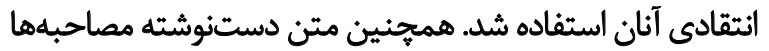

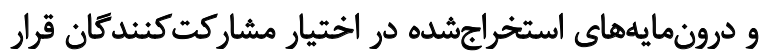

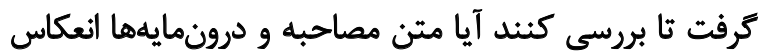
تجارب آنهاست يا خير. براى افزايش انتقال يذينيرى و وتناسب،

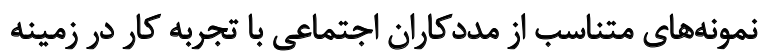

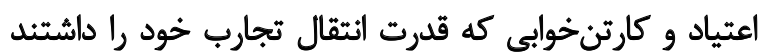

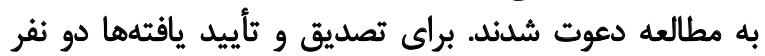

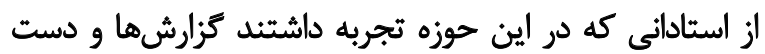

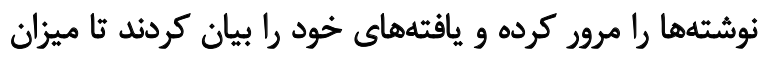

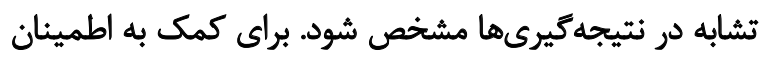

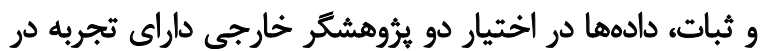

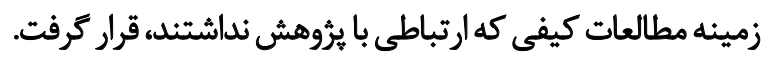

يافتهها

در اين يثروهش بيست نفر مشاركت داشتند كه يافتههاى حاصل

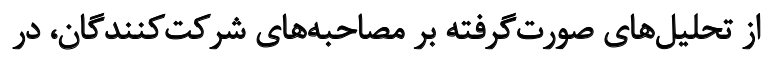

\footnotetext{
1. Actions

2. Interactions

3. Emotions

4. Outcomes

5. Consequences

6. Credibility

7. Transferability

8. Conformability

9. Dependability
} 
جدول ا. واحد معنا، كد اوليه، طبقات و مفاهيم اصلى استخراجشده از مصاحبهها

gllo

كد اوليه

طبقات

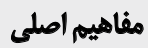

اردبيل شهر كوجكى است براى اينكه رسوا شدم وخانوادام لطمه نخورند به تهران أمدم .$(T-I T)$

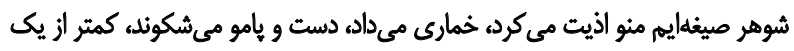

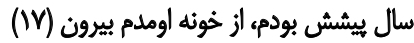
از خونه فرار كردم جون با مادرم مشكل داشتم (If)

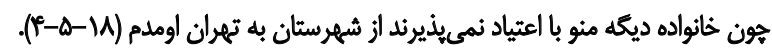

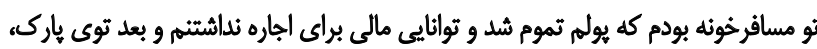

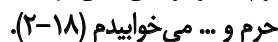

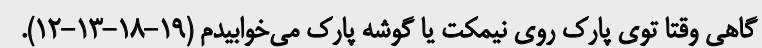

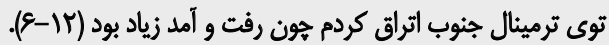

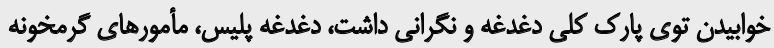

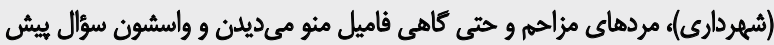

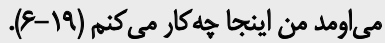

خرج زندكى رو از طريق سيكار و فندى، سنجاتفروشى، ضايعات و ... تأمين مى مكدم . (p-11)

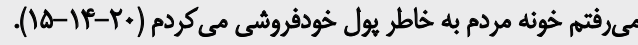

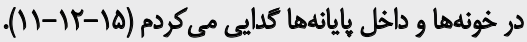

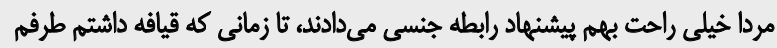

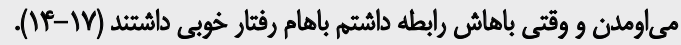

از اين ميثرسيدم كه با كارتنخواباى ديكه كه هستم به خاطر جرم نكرده با بقيه مجرما

$$
\text { برو زبندان (19). }
$$

به كارتن خوابا آسيبي نمىرسوندم و باهاشون خوبم و اونا هم هواي منو دارن (IT).

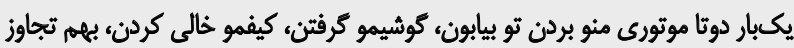

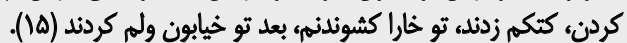

اكثر قاجاق فروشها جوون بودن شيشه مي كشيدن، توهم مىزدند و دختراي كارتن خواب

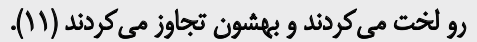

تا زمانى كه قيافه داشتم طرفم مى اوملن و وقتى باهاثون رابطه داشتم باهام رفتار خوبى داشتند (IV-IF).

خوابيدن تو يارى خطر داره مثلاً ممكنه جييتو معثاداي ديكه بزئندو يا اينكه آسيب

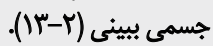

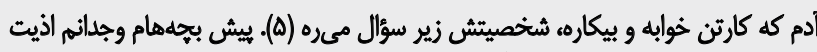

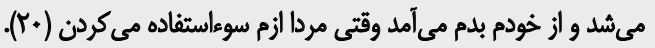

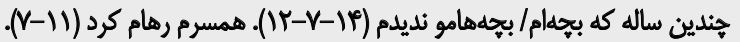

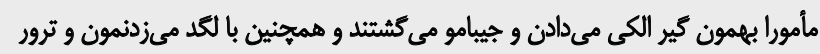

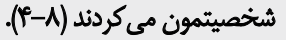

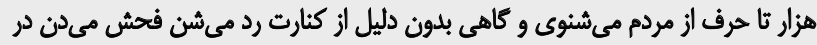

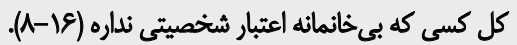

دورى حفاظتك كنده از خانواده

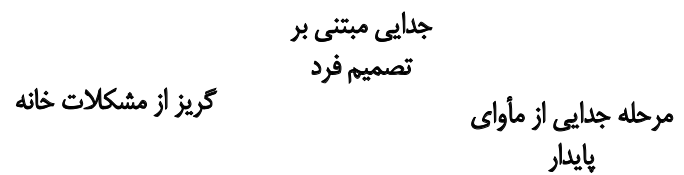

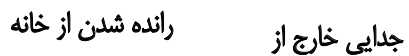

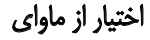

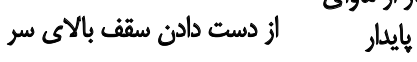

$$
\text { ماواكزينى در اماكن عمومى }
$$

ماوواكزينى كريزكراياته

ماواكزينى

كريزان

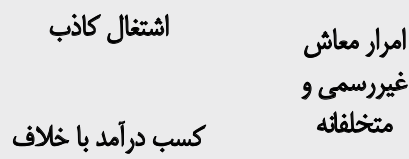

قرار كرفتن در ييوندهاى بالقوه

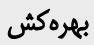

بنبكة روابط

آزارديدكى هاى اجتماعى ويثه

زئنان

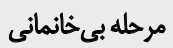

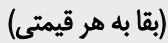

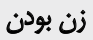

زيبايمى زنانه اغواكرانه

تفاوتهاى

جنسيثى - جنائ

هختصات ماواكزينى خيابائى

خطر آسيبهاى (مالى

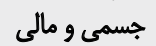

دروثىسازى هويت مخحدوش

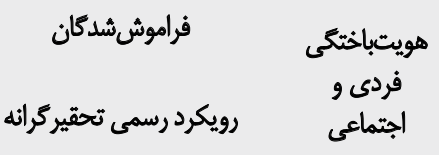

بيى اعتبارشدكان اجتماعى 


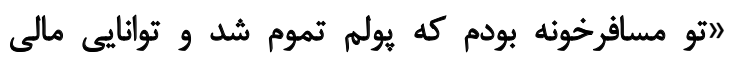

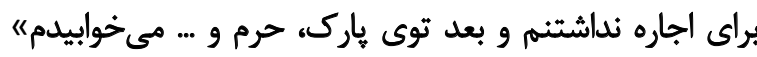

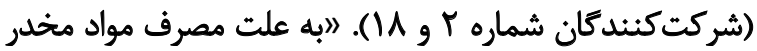

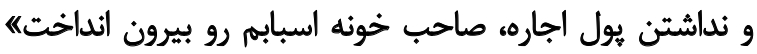

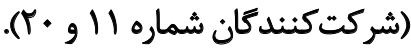
مرحلا بي خانمانى شرايطزمينهاى مرحله بيىخانمانى از سه مقوله تشكيل شده است: مأواكزينى

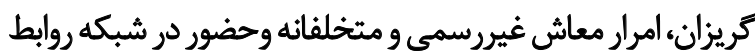

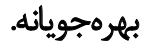

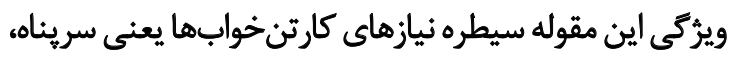

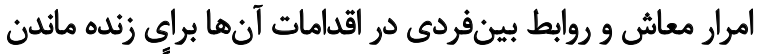

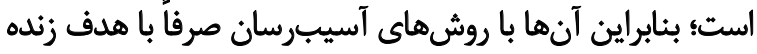

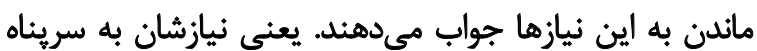

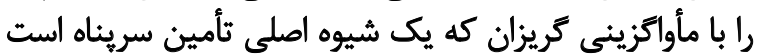

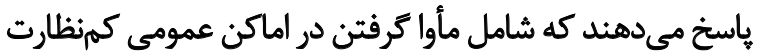

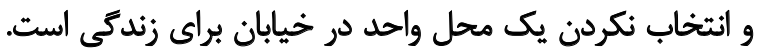

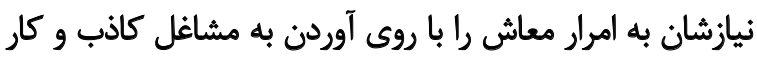

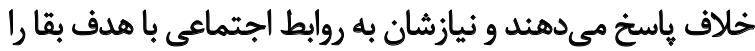

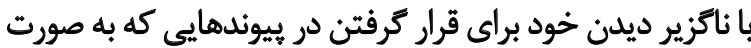

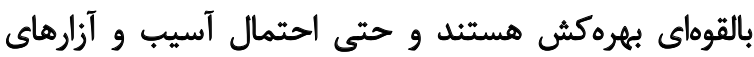
جنسيتى در آن است، ياسخ مي دهنئد

\section{مأواتزينى جريزان}

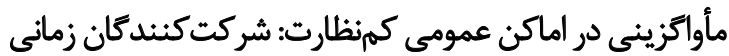

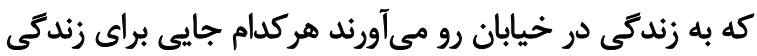

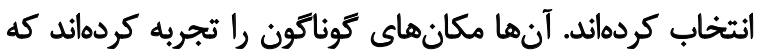

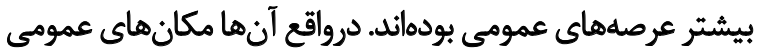

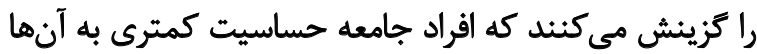
داشته باشند مثل ياركها و غينده افراد جامعه

"اكاهى وقتا توى بارك روى نيمكت يا كوشه بارك، ترمينال

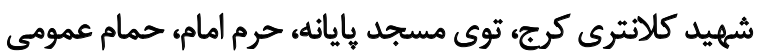

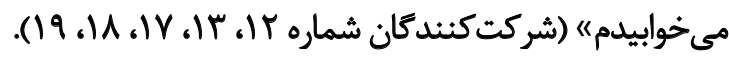

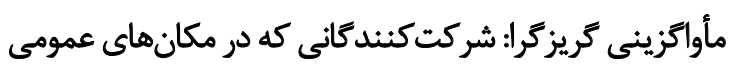

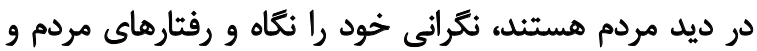

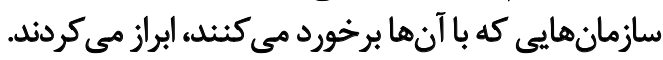
"احساس ترس از كير دادن نيروى انتظامى داشتمه"

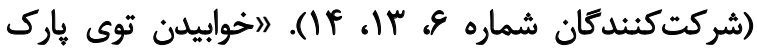
كلى دغدغه و نكرانى داشت، دغدئه

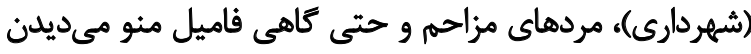

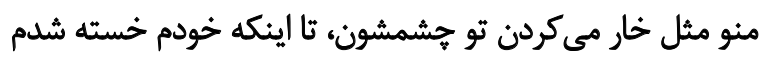
و يك شب زدم بيرون و ديكة برنكشتم خونه

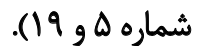

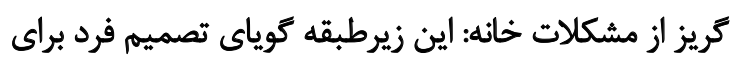

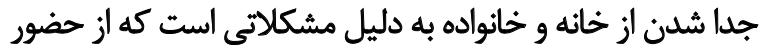

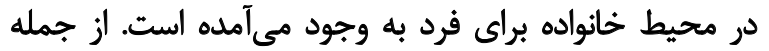

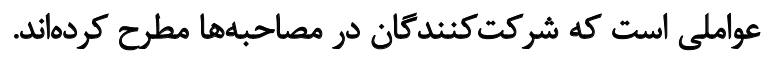

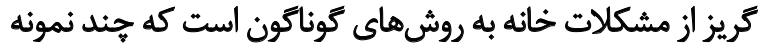

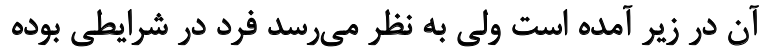

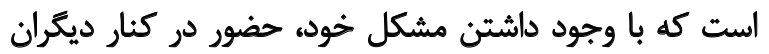

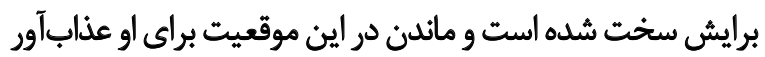

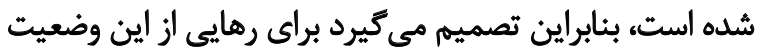

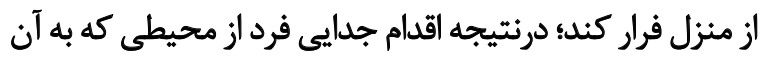

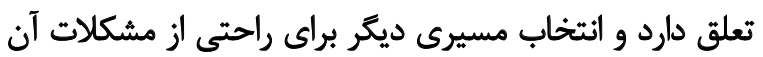
مجيط اسيت.

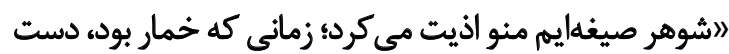

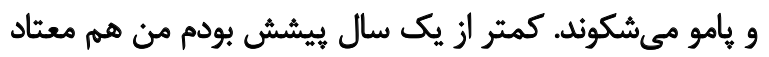

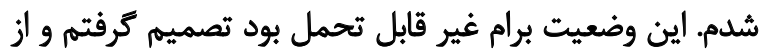

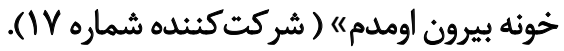
(از خونه فرار كردم جون با مادرم مشكل داشتمه (شركت كنثنه

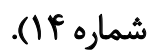
"جون خواستم از مصرف مواد خلاص بشم (جون اونجا همه مصرف مى كردند) از خونه بيرون زدم) (شركت مكننده شماره f).

\section{جدايى خارج از اختيار از مأواى يايدار}

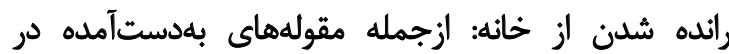

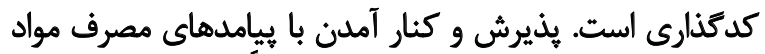

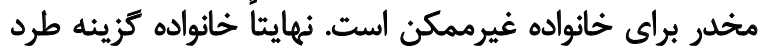

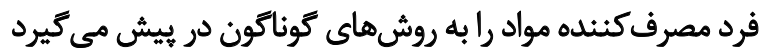

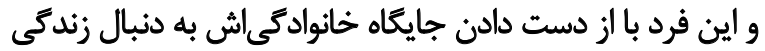
جديد در خيابان و خانواده جديد مي إنورد.

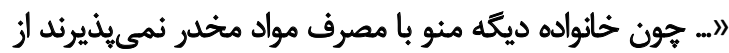

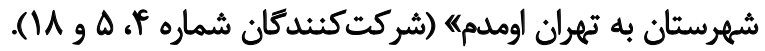

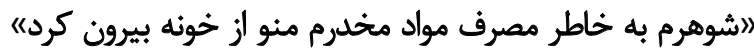

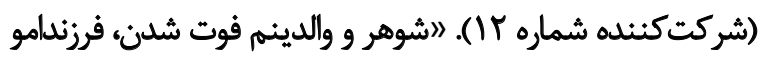

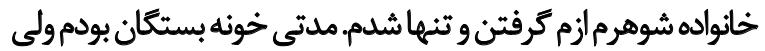

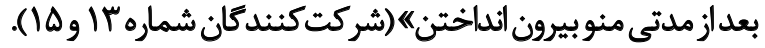

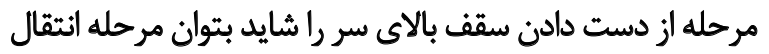

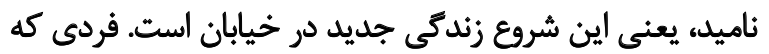

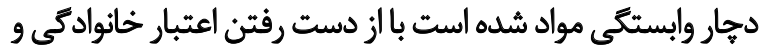

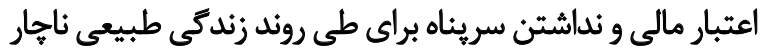
در شرايطى قرار مى كيرد كه بايد آن را بيذيرد. 
كردم و طى اين مدت جون جوون بودم امكان داشت دوستام منو

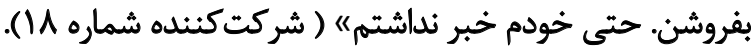

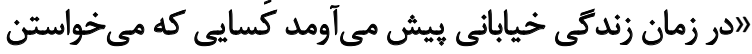

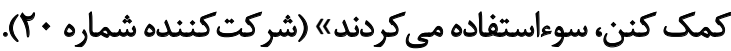

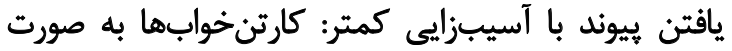

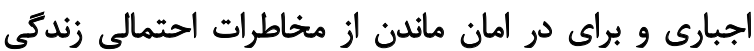

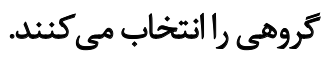

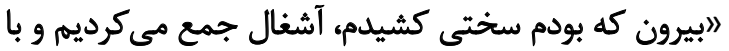

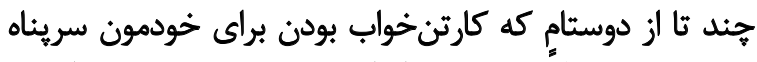

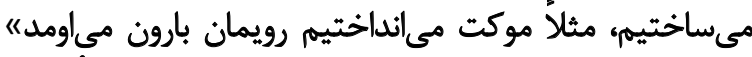

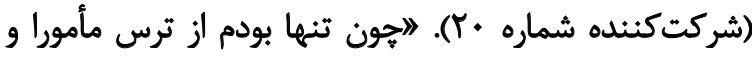
اطرافم مجبور بودم باديگر كارتن خوابها باشمه (شركت كنندكان

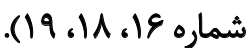

$$
\text { شرايط مداخله }
$$

\section{تفاوتهاى جنسيتى}

بر اساس تجربه شركت كنندكان تحقيق، تفاوتهاى جنسيتى

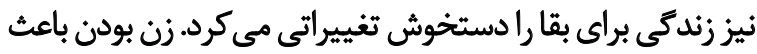

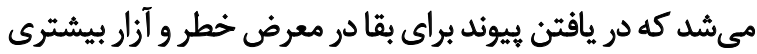

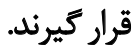

״اكثرقاجاق فروش هاجوان بودن، شيشه مي كشيدن، توهم ميزدن

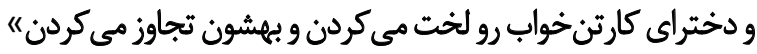

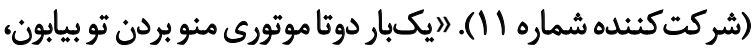

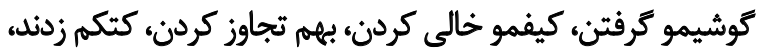

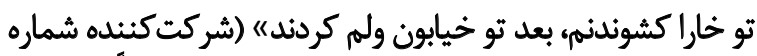

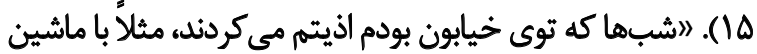

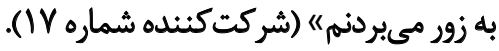

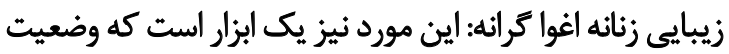

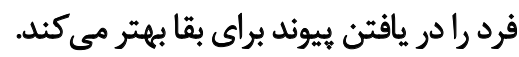

"اتنا زمانى كه قيافه داشتم طرفم مى اومدن و وقتى باهاشون

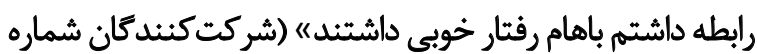
(IV, If

\section{خطر آسيبهاى جسمى ومالى}

زندگى كارتن خوابى در بسترى از خطرات صورت مي گيرد. اين

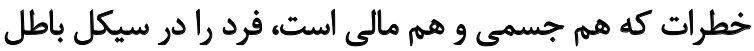

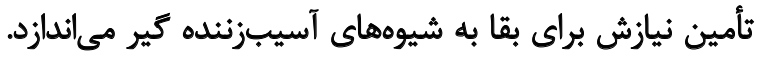

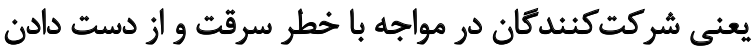

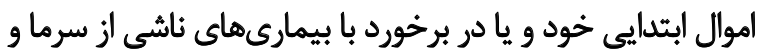

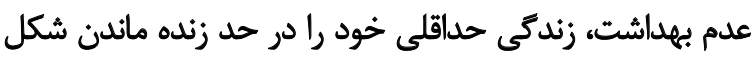

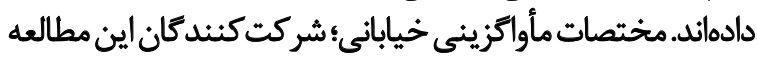

و واسشون سؤال بيش مى واومد من اينجا جهكار مي كنمه (شركت كنيدكان شماره و و و 19).

\section{امرار معاش غير رسمى و متخلفانه}

اشتغال كاذب: برخى افراد مطالعشده كه در خيابان حضور

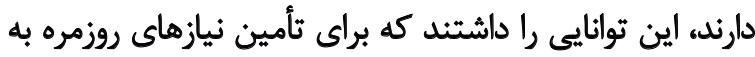

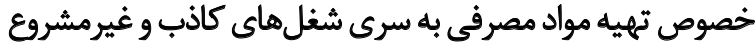

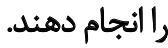

"ضايعات جمع مىكردم" (شركتكنيده شماره f). "اخرج

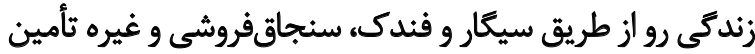

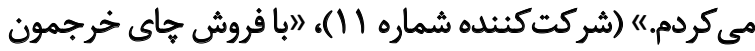

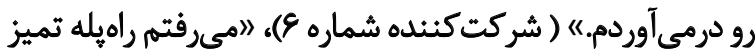

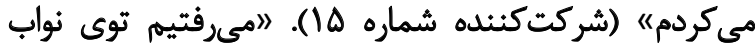
تراكت يخش مى كرديم" (شركت كنثنه شماره 11)

كسب درآمد با خلاف: افراد از دو جنس با توجه بـ به موقعيتهاى

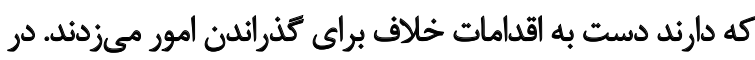
اينجا اين تجربيات متفاوت رادر قالب جملات نشان مى بدهيه.

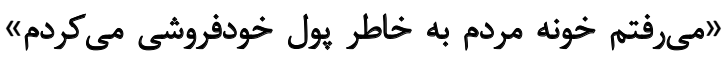
(شركتكنئدكان شماره

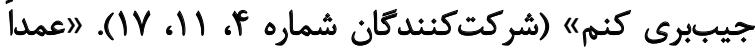

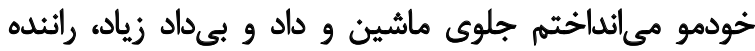

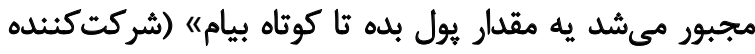

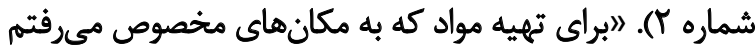

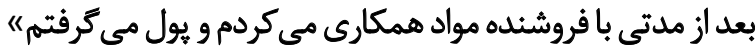
(شركت كنيندكان شماره بو و ع).

\section{حضور در شبكه روابط بهرهجويانه}

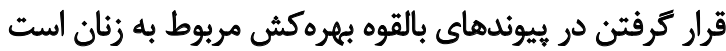

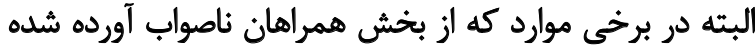

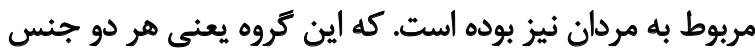

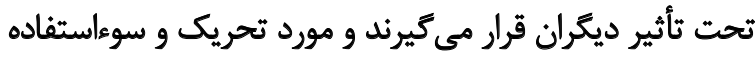
قرار مى تصيرند.

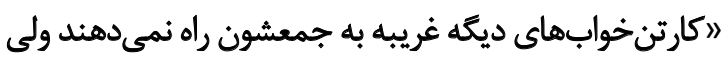

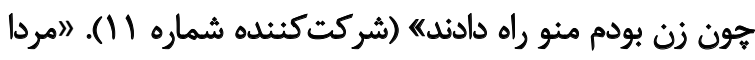

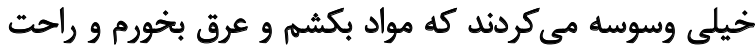

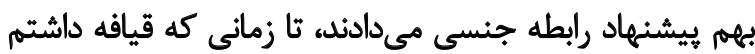

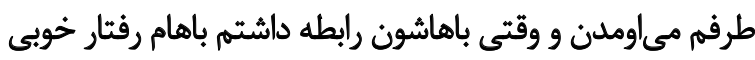

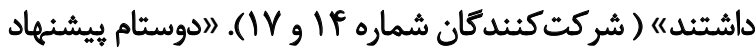
مى دادن بريم خودفروشى مى تَفتن خوشئل

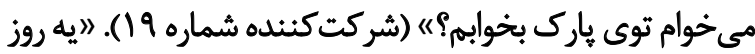

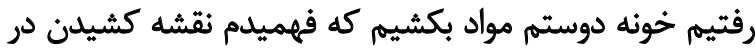

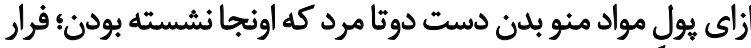




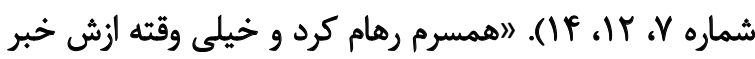

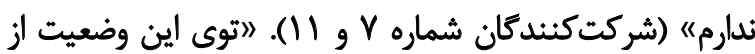

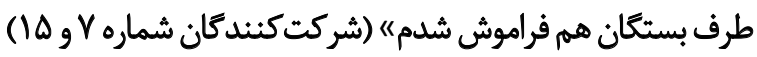
روش معمول در تحقير كردن: اين مفهوم اشاره به رفتارهاي

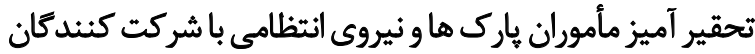

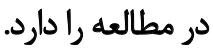

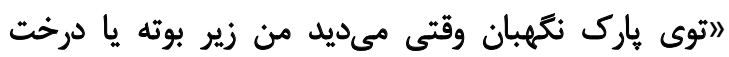

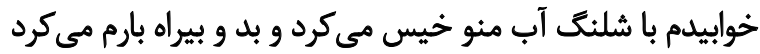

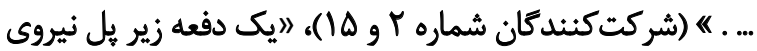

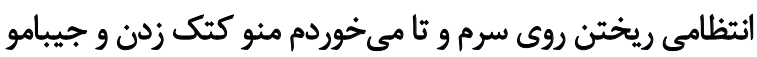

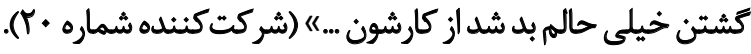

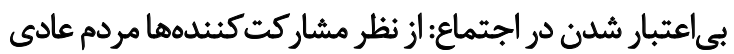

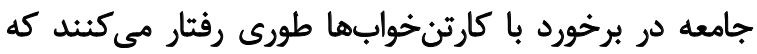

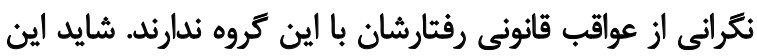

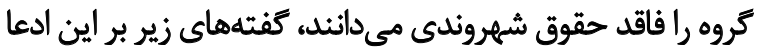
صحه مى كذارند. "يك سرى از مردم توهين و تحقير مي كنيند. (شركت كنينده

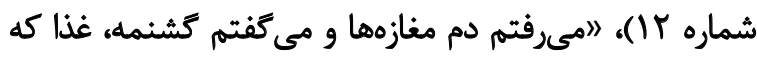

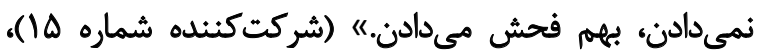

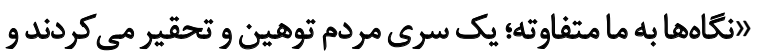

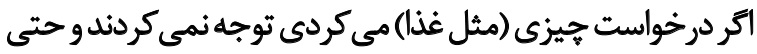

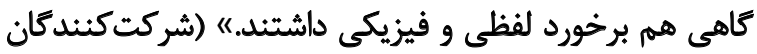

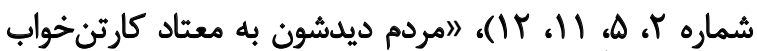

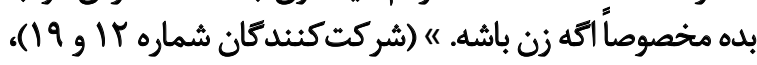

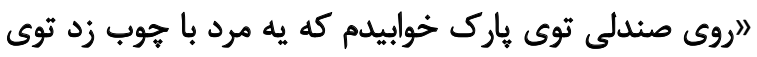

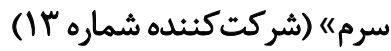
Sرg بقا به هر قيمتى

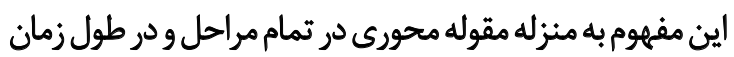

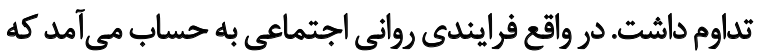

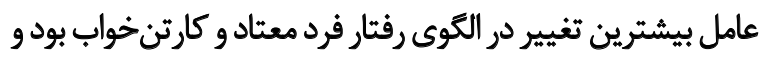

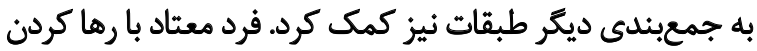

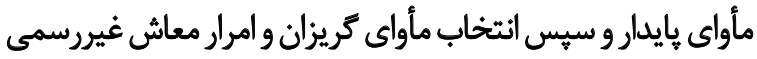

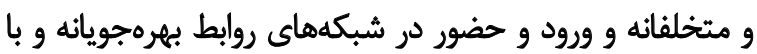

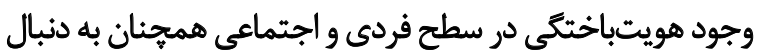
حفظ زندكى و بقا خود به هر قيمت بودي

$$
\text { بارادايمئذارى }
$$

با توجه به موارد مطرحشده در تصوير شماره ا 1 فرايند كارتن خوابى مصرفكنينده مواد مخدر در قالب مدل مدل ارائه شد.
در خصوص حضور در خيابان با توجه به سختى هاو مشكلات آن

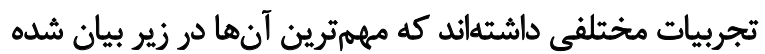

"اخوابيدن تو يارى خطر داره مثلاً ممكنه جيبتو معتاداي ديكه

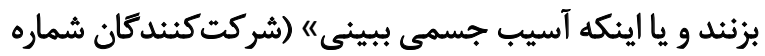

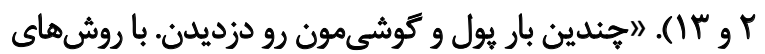

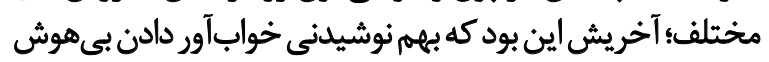

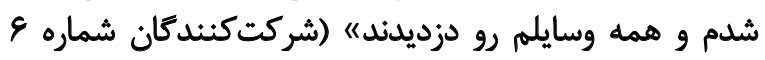

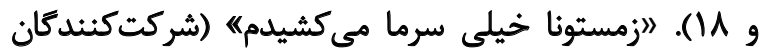

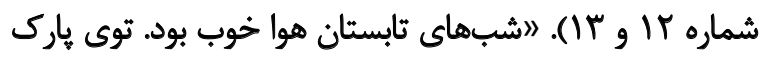

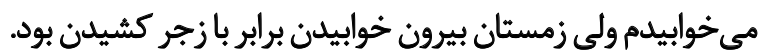

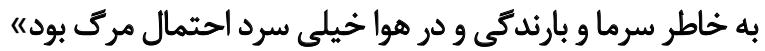

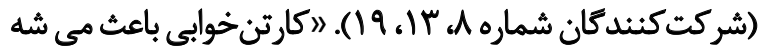

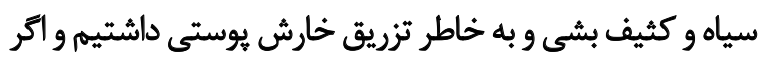

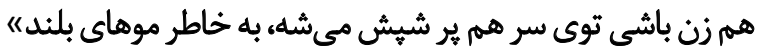

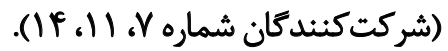

بيامد

\section{هويتباختكى فردى واجتماعى}

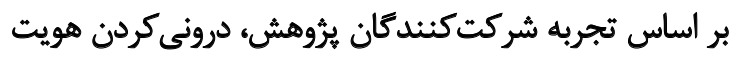

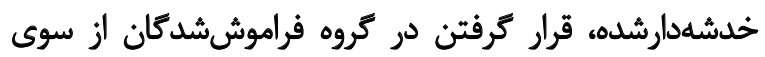

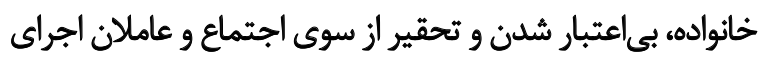

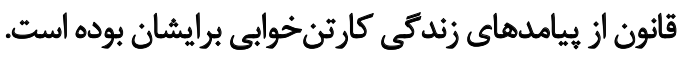

درونىسازى هويت خدشهدارشده؛ برخى كارتن إخوابها

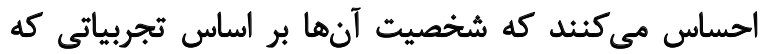

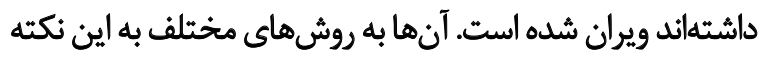
اعتراف مى كردند.

"آدم كه كارتن خوابه و بيكاره شخصيتش زير سؤال مىرهارها

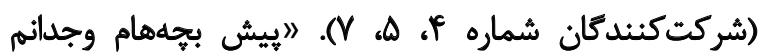

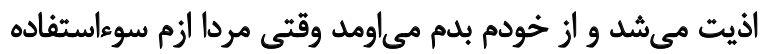

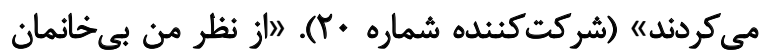

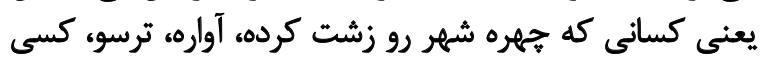

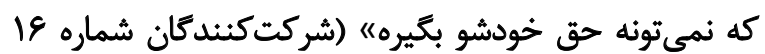

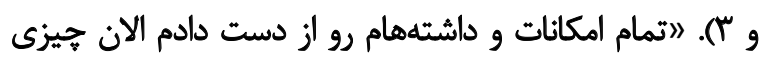

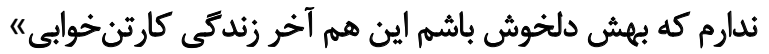

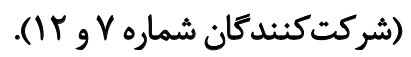

قرار كرفتن در كروه فراموششدكان: شركت كنندكان طى

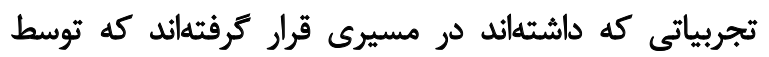

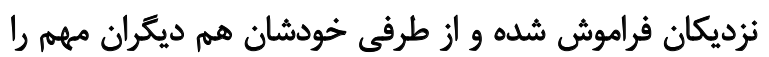

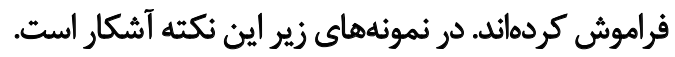
"جندين ساله كه بحهام / بحههامو نديدم" (شركتكنئدكان 


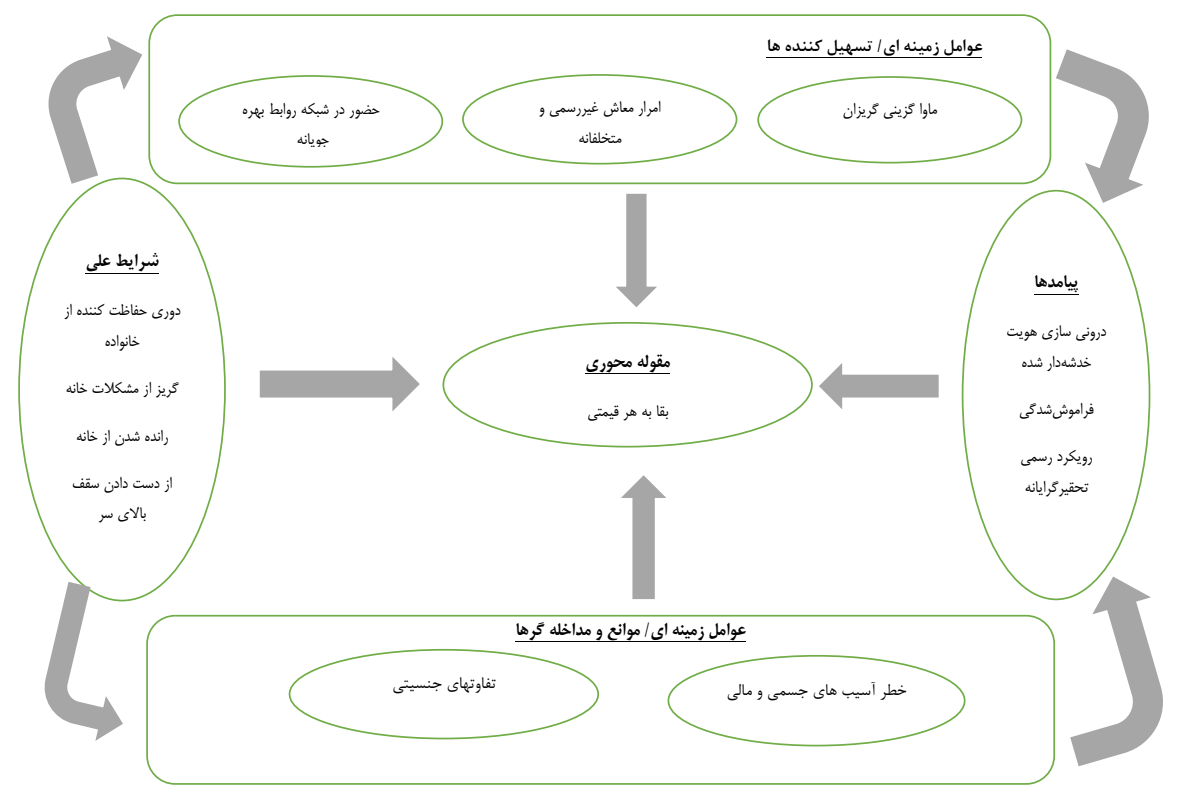

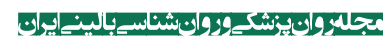

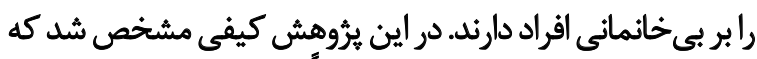

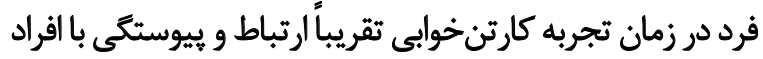

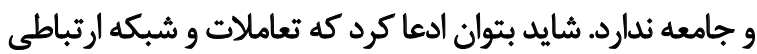

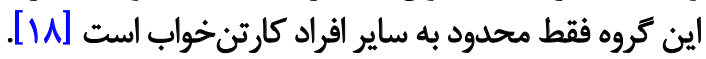

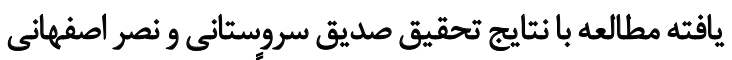

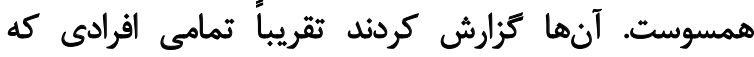

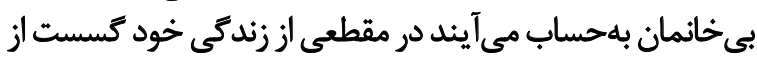

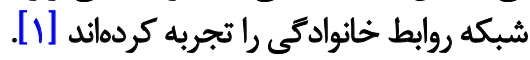

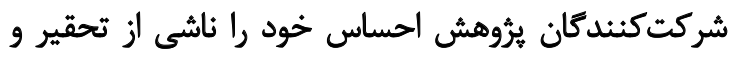

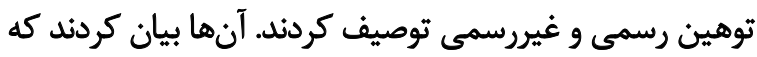

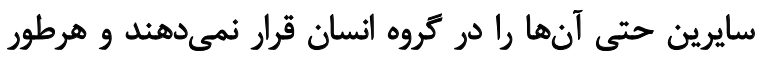

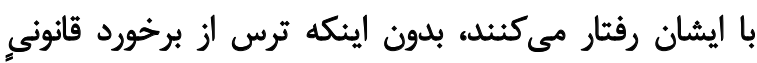

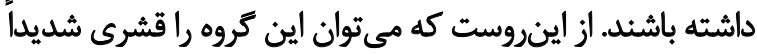

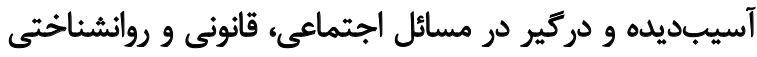
كوناكون دانست.

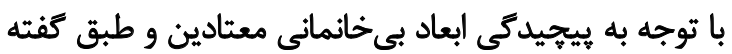

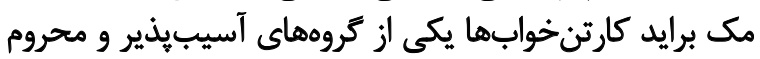

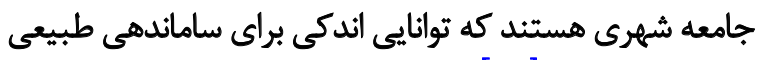

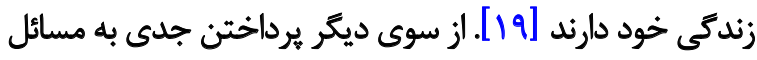

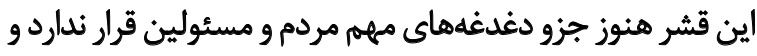

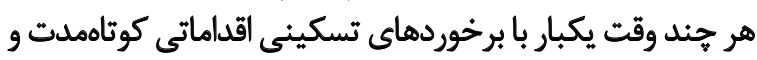

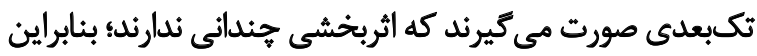

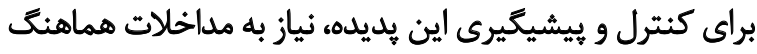
بين فرد، خانواده و سيستمهاى ائ حمايت بننيده در تمام سطوح

\begin{abstract}
تصوير ا. مدل كارتنخوابي معتاد
در يافتههاى اين يثروهش مشخص شد كه در مرحله نخست

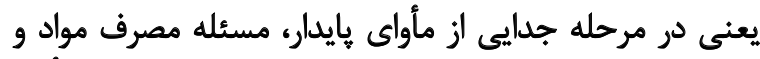

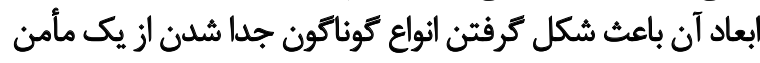

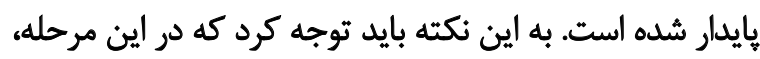

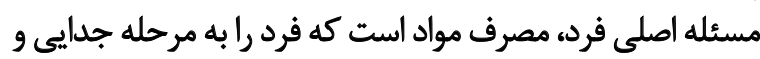

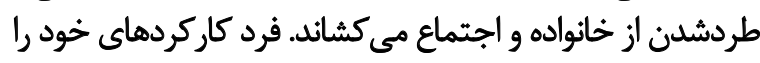

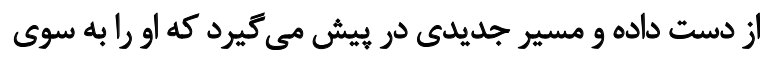

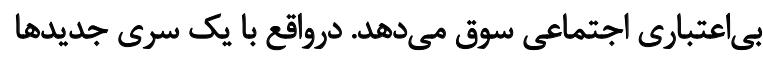

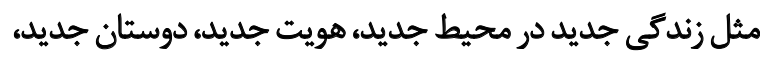

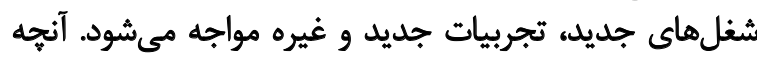

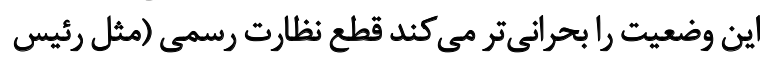

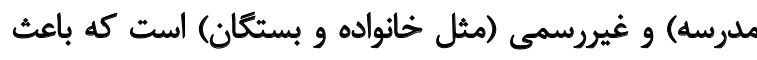

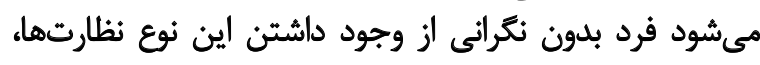

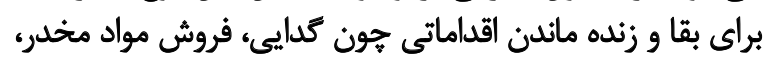
جيببرى، خودفروشى و غيره را انجام دهد انداني

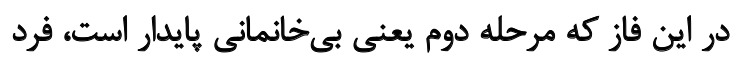

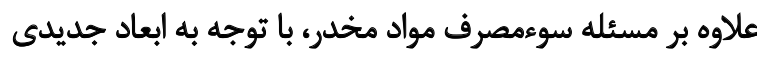

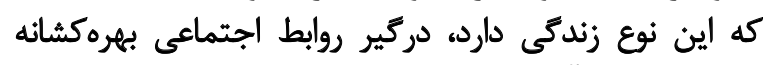

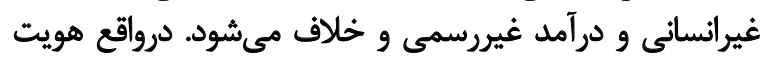

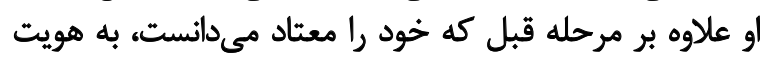

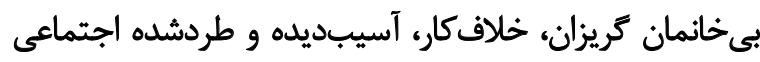

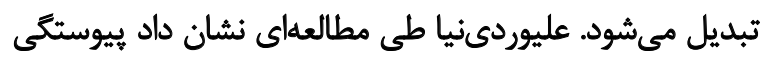

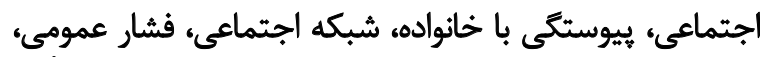

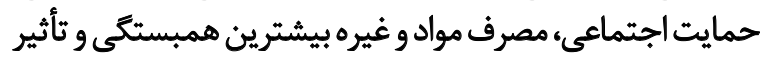




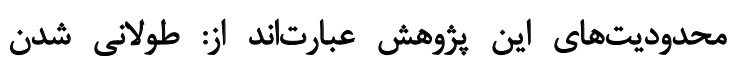

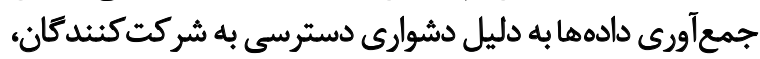

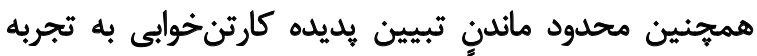

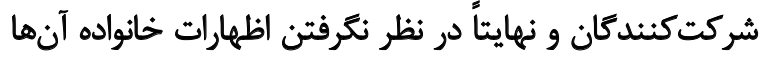
به دليل عدم دسترسى.

ملامطاث اخلاقي

\section{بيروى از اصول الخلاق يثروهش}

اصول اخلاقى تماماً در اين مقاله رعايت شده است. شركت

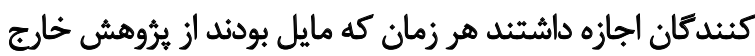

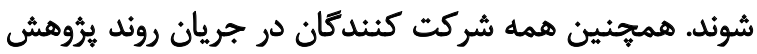

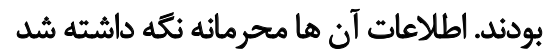

$$
\text { مامي مالى }
$$

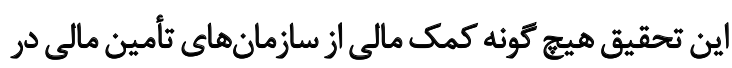
بخشهاى عمومى ، تجارى يا غير انتفاعى دريافت أنس نكرد.

$$
\text { مشاركت نويسند أنان }
$$

تمامى نويسند

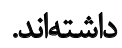

$$
\text { تعارض منافع }
$$

بنابر اظهارنويسندكان اين مطالعه هيجكونه تعارض منافعى

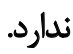

در تحقيق صديق سروستانى و نصر اصفهانى سه عامل مهام و و واني

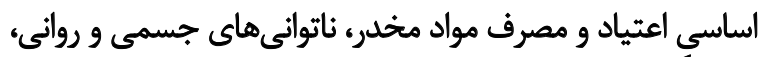

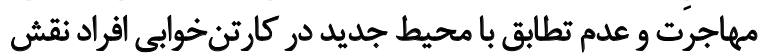

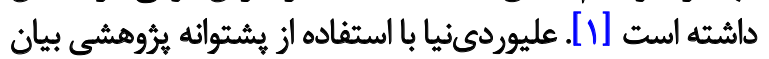

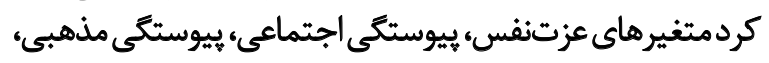

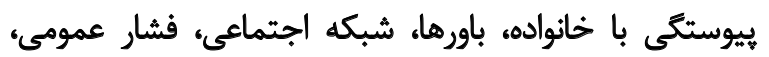

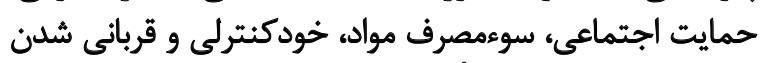

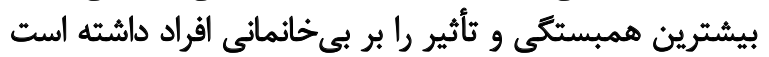

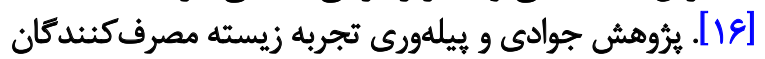

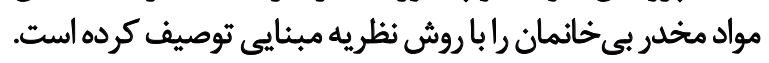

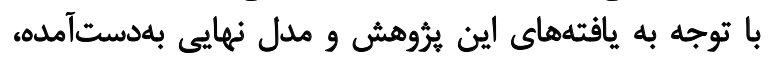

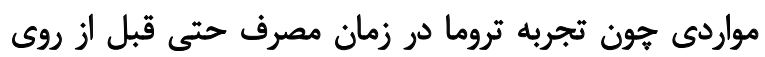

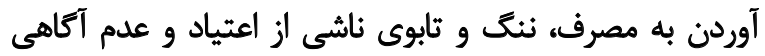

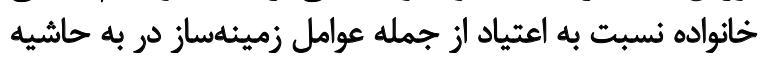

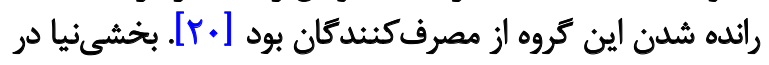

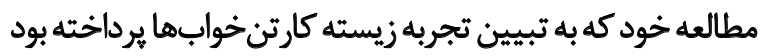

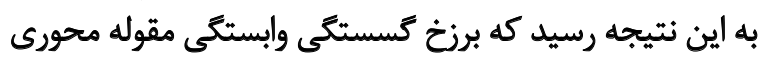

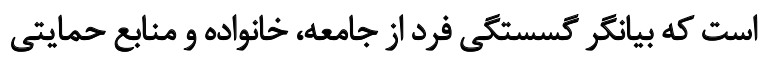

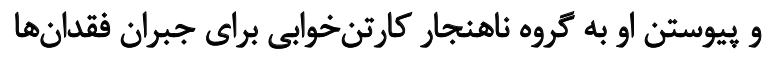

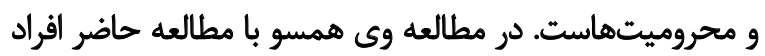

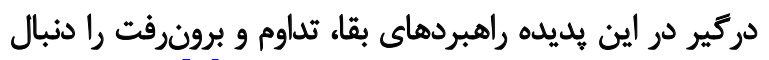

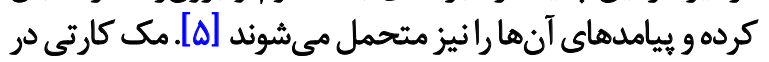

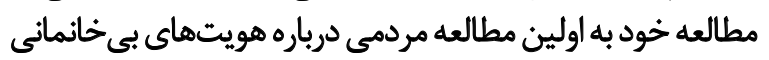

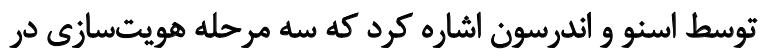

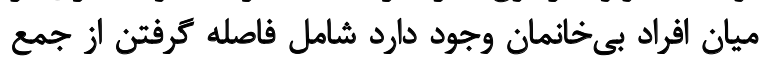

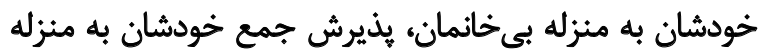

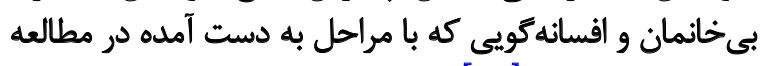

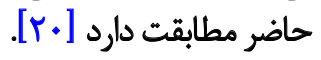

\section{نتيجنهيرى}

مطالعه حاضر به بررسى فرايند كارتنخواب شدن معتادان

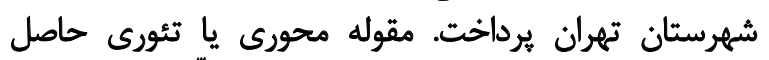

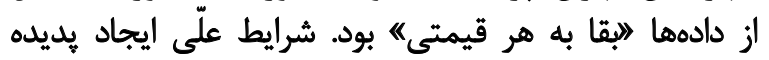

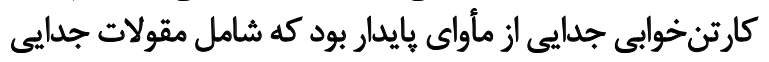

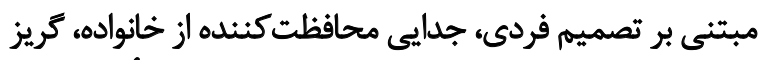

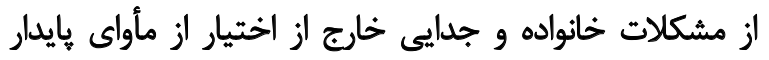

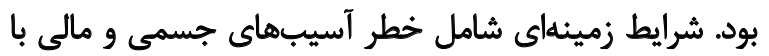

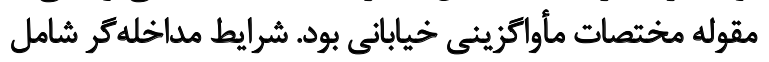

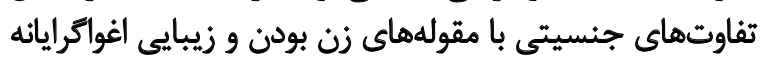

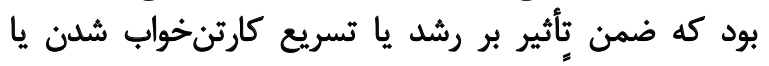

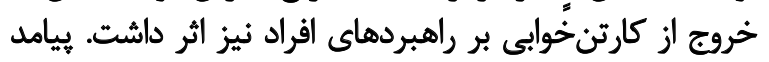

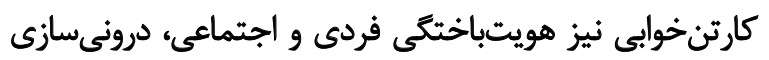

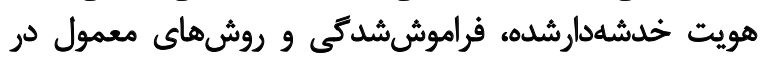
تحقير فرد را به دنبال داشت. 


\section{References}

[1] Sedigh Sarvestani R, Nasr Esfahani A. [Drug abuse, social exclusion, and homelessness in Tehran: A qualitative study (Persian)]. Journal of Social Problems of Iran. 2011; 1(4):504521. https://ijsp.ut.ac.ir/article_22692.html?lang=en

[2] Anker J. Organizing homeless people: Exploring the emergence of a user organization in Denmark. Critical Social Policy. 2008; 28(1):27-50. [DOI:10.1177/0261018307085506]

[3] Sajjadi S, Kamal SH, Darzi HA. The socioeconomic status of street homeless in Tehran. Advances in Environmental Biology. 2014; 1297-304. https://go.gale.com/ps/i.do?id=GALE\%7CA3 $85404606 \&$ sid $=$ googleScholar\& $v=2.1 \& i t=r \&$ linkaccess $=$ abs\&iss $\mathrm{n}=19950756 \& \mathrm{p}=\mathrm{AONE} \& \mathrm{sw}=\mathrm{w}$

[4] Bakhshi Nia A. Understanding the lived experiences of people sleeping rough in Tehran. A Research Journal on Social Work. 2017; 3(11):214-62. [Doi:10.22054/RJSW.2017.9657]

[5] O'Toole TP, Gibbon JL, Hanusa BH, Freyder PJ, Conde AM, Fine MJ. Self-reported changes in drug and alcohol use after becoming homeless. American Journal of Public Health. 2004 94(5):830-5. [DOI:10.2105/AJPH.94.5.830] [PMID] [PMCID]

[6] Early DW. An empirical investigation of the determinants of street homelessness. Journal of Housing Economics. 2005; 14(1):27-47. [DOI:10.1016/j.jhe.2005.03.001]

[7] Edens EL, Kasprow W, Tsai J, Rosenheck RA. Association of substance use and VA service-connected disability benefits with risk of homelessness among veterans. The American Journal on Addictions. 2011; 20(5):412-9. [DOI:10.1111/j.15210391.2011.00166.x] [PMID]

[8] Aghaei SS, Kaldi A, Vosooghi M. [The role of urban area on Homeless people's daily life in Tehran (Persian)]. Sociology Studies. 2018; 10(37):7-24. http://jss.iaut.ac.ir/article_537914_09 c519f2ab612a56c3e3321ba3243d2a.pdf

[9] Morgan WJ. Escaping from homelessness. [PhD. Dissertation]. Warwick: University of Warwick. http://wrap.warwick. ac.uk/49320/1/WRAP_THESIS_Morgan_2011.pdf

[10] Washington PS. A grounded theory study of substance use patterns among homeless youth. Texas: ETD Collection; 2009. http:/ /hdl.handle.net/2152.3/145

[11] Salarzadeh Amiri N, Mohammadi B. [Investigating the effects of socio-economic factors on homeless people of Tehran (Persian)]. Social Development and Welfare Planning. 2010; 1(1):39-110. https://www.sid.ir/en/journal/ViewPaper. aspx?id=174386

[12] Clapham D. Homelessness and social exclusion. West Sussex: John Wiley \& Sons Ltd; 2007. [DOI:10.1002/9780470773178.ch5]

[13] Environment \& Urbanization. Social exclusion and housing - context and challenges [Internet]. 2000 [Updated 2000]. Available from: https://www.environmentandurbanization.org/ print $/ 2343$

[14] Safiri K, Khadem R. An evaluation of life expectancy status among homeless women in tehran city (case of study: a temporary holding center for homeless women of tehran municipality, "samansraye lavizan"). Journal Of Iranian Social Development Studies (Jisds). 2014; 6(1 (21)):51-70. https:/ /jisds.srbiau.ac.ir/art icle_3157_57c283a854dea4ee78fec625aa87c47a.pdf?lang=en
[15] Safiri Kh, Khadem R. [An Evaluation of Life Expectancy Status among Homeless Women in Tehran City (Case of study: A Temporary Holding Center for Homeless Women of Tehran Municipality, "Samansraye Lavizan") (Persian)]. 2014; 6(1):5170. https://jisds.srbiau.ac.ir/article_3157.html

[16] Polit DF, Hungler BP. Nursing research: Methods, appraisal, and utilization. Philadelphia: Lippincott; 1993.

[17] Aliverdinia A, Pridemore WA. A first glimpse at narcotics offenders in an Islamic Republic: A test of an integrated model of drug involvement among a sample of men incarcerated for drug offenses in Iran. International Criminal Justice Review. 2007; 17(1):27-44. [DOI:10.1177/1057567706298913]

[18] Mcbride RG. Survival on the streets: Experiences of the homeless population and constructive suggestions for assistance. Journal of Multicultural Counseling and Development 2012; 40(1):49-61. [DOI:10.1111/j.2161-1912.2012.00005.x]

[19] JavadiSMH, Pilevari A. [Investigating the living experience of homeless consumers: A qualitative research (Persian)]. Quarterly Journal of Research on Addiction. 2017; 11(41):27-48. http:// ensani.ir/file/download/article/20171202084459-9704-216.pdf

[20] Mccarthy L. Homelessness and identity: A critical review of the literature and theory. People, Place and Policy Online. 2013; 7(1):46-58. [DOI:10.3351/ppp.0007.0001.0004] 
This Page Intentionally Left Blank 